\title{
A JOCIS AD SERIA: LA RISA AMBIVALENTE EN LA OBRA HUMORÍSTICA DE MANUEL VILAS
}

\author{
Cristina GutiérRez Valencia \\ Universidad de Valladolid
}

\section{INTRODUCCIÓN}

Una de las maneras más sencillas de probar la inocencia hermenéutica con la que pretendemos acercarnos a un corpus textual -en la medida en que esto sea posible- y alejarnos de una lectura estrictamente individualista y de la aplicación a priori de teorías y preconcepciones al análisis de un texto literario, es seguir los postulados de las teorías de la recepción. Si realizáramos una revisión de la recepción crítica de la obra de Manuel Vilas, encontraríamos una serie de elementos recurrentes que marcan la interpretación y el debate que sobre el autor se ha generado en España. Estos temas-estribillo, leitmotivs de las referencias críticas sobre Vilas, se podrían agrupar en los siguientes elementos: el expresionismo vitalista (Marqués 2008, A. J. Rodríguez 2008, Pozuelo Yvancos 2009, J. M. Rodríguez 2011, Mesa 2014), la tematización de la identidad a través de España (Mora 2008, Fernández Porta 2008, Benéitez 2009a, Ferré 2012), la mezcla armónica de alta y baja cultura (A. J. Rodríguez 2008, Fernández Porta 2008, Alarcón Sierra 2012), el debate sobre la enmarcación genérica de sus obras (Cilleruelo 2006, Mora 2008, Reig 2010, Gómez Trueba 2013), la pregunta sobre el carácter político de estas (Salazar 2008, Menéndez Salmón 2008, Espigado 2009, Calles 2011), la importancia del juego autoficcional (Mora 2008, Espigado 2008, Gómez Barranco 2014, Gómez 2015), y el componente de diversión y humorismo (ver apartado "Breve historia de la recepción crítica"). Esta última dimensión cómica y humorística es un asunto complejo, por la dificultad de objetivar un 
elemento que consiste más en un efecto, en un resultado, el de la risa provocada en el lector, que en algo ratificable, mensurable o cuantificable en la textualidad. El asunto del humor en las obras literarias nos obliga a plantearnos preguntas como la modalidad de humor del que estamos hablando, los recursos concretos utilizados, la delimitación que conlleva la existencia del humor en cuanto al género, la corriente o la tradición, el objetivo -lúdico, crítico, etc.- que creemos que tiene el humor en la obra (o si es un objetivo en sí mismo o un procedimiento en aras de otros fines), o la vinculación estrecha con la poética del autor, su visión de lo literario y del mundo. Todas estas preguntas deberían ir acompañadas de un cuestionamiento terminológico que valore y tenga en cuenta en su utilización términos y conceptos, tanto en su definición sincrónica como en su reconceptualización histórica: humor, humorismo, comedia, risa, sátira, parodia, ingenio, ironía, etc. son términos e ideas relacionadas entre sí, pero cuya aparición debe quedar puntualizada o enmarcada en un uso o teoría concreta, no utilizada en su acepción generalista. Además, hay un planteamiento previo, un grado cero del análisis del humor, que tiene que ver con el siempre controvertido asunto de la interpretación. La primera pregunta para hablar del humor en una obra literaria no es de carácter cualitativo, sino que nos sitúa aún en un estado de conjetura: ¿hay humor en esta obra literaria? O dicho de otra manera: ¿provoca la risa esta obra en los lectores? La pregunta sobre la existencia del humor en la obra o en su lectura exige acudir a esa breve historia de la recepción crítica de la obra humorística de Manuel Vilas. Entendemos por su obra humorística toda la parte central de su creación, narrativa y lírica, dejando fuera solamente los poemarios de formación ${ }^{1}$ y su última novela, donde comienza otro ciclo encaminado en otra dirección². El corpus lo conforman, por tanto, El Cielo, Resurrección, Calor, Gran Vilas, Zeta, Magia, España, Aire Nuestro, Los inmortales, Listen to me y Arde el sol sin tiempo.

\section{BREVE HISTORIA DE LA RECEPCIÓN CRÍTICA}

Comencemos, por tanto, por aplicar la pregunta sobre el humor a la obra literaria de Manuel Vilas y veamos los resultados en esa sucinta cronología crítica que van formando las reseñas, artículos y entrevistas sobre su obra. Al respecto de Zeta, su primer libro de relatos, Sara Mesa (2014) habla de "un autor con un ingenio indiscutible y un sentido del humor amargo, desesperanzado y, a la vez, tremendamente vitalista". Sostiene que "él reía y todos reíamos. Justo esa es la magia de Zeta, la mezcla de luminosidad y negrura". Javier Divisa (2014), por su parte, dice de estos relatos que "Ilevan medio de sonrisa y un cuarto de estupor". Para él la clave "se Ilama ironía. Reír llorando". Pedro Pujante (2014) opina que

\footnotetext{
${ }^{1}$ En su Poesía reunida, que recopila en 2010, apenas incluye unos pocos poemas de todos los poemarios anteriores a El Cielo, y él mismo señala en otro lugar: "construí una ceremonia libertaria, llena de lenguaraz literatura, en torno a mi propia identidad. Creo que todo arrancó a partir de la publicación de mi libro de poemas El Cielo (2000)" (Vilas 2014a: 254).

2 "Tanto Los inmortales como Gran Vilas creo que cierran un ciclo. No puedo ir más lejos por alli" (Consuegra 2012).
} 
"su ironía y su humor -negro, pero un negro posmoderno, o sea, inclasificable y socarrón- nos persiguen y nos iluminan".

Sobre España, su segunda novela, Eloy Fernández Porta (2008) destacaba "la crucifixión, representada aquí con un sentido más propio de los Monty Python que de la Biblia. De este modo el anhelo de Eternidad que recorría la primera época del autor reaparece, en versión bufa". Ricardo Menéndez Salmón (2008) cree que "para escribir un libro político, a pie de obra, un libro armado con vocación de molestar, nada más certero que disfrazar la indignación de ironía y arremeter contra todo lo que se mueve entre el cielo y la tierra". David Mayor (2008: 412) afirma que "Vilas construye una voz tragicómica que se ríe de sí misma como Cristo resucitado" y Edmundo Paz Soldán (2008) manifiesta que la obra es "una lectura irónica y alucinada del pasado, el presente y el futuro de España". Juan Francisco Ferré (2008) insiste en que Vilas narra "asumiendo el diagnóstico de la necrosis con humor incomparable", creando "una divertidísima invitación al desahucio de los podridos fantasmas que vampirizan desde hace siglos la identidad española".

En cuanto a su poemario Calor, Juan Marqués (2008: 105) argumenta que "ese es el modo que ha encontrado Vilas de denunciar: un modo antisolemne, irónico, gamberro y relativamente desenfadado (pero no exactamente lúdico)". Luis García Jambrina (2008) proclama que el poemario es "uno de los libros más provocadores y desopilantes de los últimos años", a la vez que Rafael Suárez Plácido (2009) sostiene que "Vilas también nos hace reír y llorar en un mismo poema", que "libertad de pensamiento y humor son su tabla de salvación" y que "ni siquiera en los momentos más duros abandona el humor ni la ironía". Ángel Guinda (2009: 202) cree que su poesía tiene "un humor somarda que la hace incluso divertida donde más duele".

Analizando Aire nuestro, Antonio J. Rodríguez (2009: 96) cree que "resulta difícil determinar si Aire nuestro es como contar un chiste dos veces seguidas", pero afirma también que "cuando la broma no cae en picado hacia el lugar común o el esbozo [...], el humor, así como la ambigüedad ideológica, siguen siendo dos de los milagros más reconocibles en la factoría zaragozana". Alberto Olmos (2009) añade a la interpretación de la novela "un sesgo social (es decir: de cierta denuncia) que se solventa con humor negro", José María Pozuelo Yvancos (2009) asegura que "es condición del libro el humor, tanto en las situaciones [...] como en los diálogos de muertos", e insiste en "el humor (tan raro hoy), que Manuel Vilas recupera para la sátira, hermanada otra vez con la novela en un vitalismo festivo digno de aplauso". Marta Caballero (2009) también asevera que "ha querido, fundamentalmente, pasárselo bien. Más que criticar, reír -y de verdad que se ríe-"; Ramón Acín (2010) destaca "la presencia o uso de la ironía, la acidez soterrada, el humor festivo, la carcajada".

Respecto a Amor, su poesía reunida en 2010, Josep María Rodríguez (2011: 141), ampliando el campo de visión, aclara que "el humor es uno de los ejes vertebradores de la escritura de Manuel Vilas. Igual en poesía que en prosa [...]. Aunque se trata de un humor muy singular, que nace como reivindicación de la existencia". 
A la hora de abordar la novela Los inmortales Emma Rodríguez (2012) subraya que Vilas "vuelve a compaginar en Los inmortales humor y crítica, comedia y trascendencia". En opinión de Santos Sanz Villanueva (2012) la obra se caracteriza por "una libérrima creatividad que transgrede las convenciones de espacio y de tiempo y que aplica un humorismo dislocado, vanguardista y revulsivo" y "se balancea entre la comedia y la tragedia, entre el humor lúdico y lo grotesco".

Por último, fijándose en esa suerte de dietario que es Listen to me, Javier Llamazares (2014) declara que "sin duda el libro más divertido de la temporada es Listen to me, [...] con un estilo tan mordaz como desenfadado, [...] a fuerza de ingenio y de un humor desbordante"

De este muestrario de referencias críticas podemos sacar algunas conclusiones: la primera de ellas es que las obras de Manuel Vilas son divertidas o son leídas en clave de humor por una representación importante de sus lectores. Esta conclusión, que parece bastante clara dado el volumen de referencias del que se deduce, obvia, sin embargo, todos aquellos textos críticos que, refiriéndose también a la obra de Manuel Vilas, no mencionan el humor en ninguna de sus variantes (Cilleruelo 2006, Mora 2008, Benéitez 2009a, Espigado 2009, o Reig 2010, por ejemplo). Podríamos fijarnos en que no hemos encontrado ninguna crítica que se refiera al componente cómico al juzgar su primera novela, Magia (es cierto que la cantidad de reseñas y críticas totales de esta obra es mucho menor que en obras posteriores), y que las alusiones a la risa en su primera obra narrativa, Zeta, se dan todas en críticas elaboradas a raíz de la reedición de la obra en 2014; es decir, que las lecturas humorísticas que aportamos de Magia podrían estar cabalmente influenciadas por las obras posteriores de Vilas, de más clara recepción humorística.

Una segunda conclusión sería que, a la vista de las aseveraciones presentadas, el humor que se observa en las obras de Vilas no es siempre el mismo, esto es, evoluciona: podríamos, fijándonos en las palabras clave de las referencias, trazar una línea general desde el humor oscuro o amargo de Zeta, un humor más negro, hacía un humor tragicómico, irónico, de reír llorando de las obras de la etapa central, hasta un humor más festivo en Aire nuestro, Los inmortales o Listen to me. El mismo Vilas así lo entiende cuando habla de sus primeras obras narrativas desde la perspectiva del presente, en una entrevista con Francisco Camero (2014): "Zeta es muy oscuro, muy rabiosamente desolador; mis libros posteriores ganarán en celebración y exaltación de la vida; ganarán en un humor más amable y menos sombrío. El humor en Zeta es destructivo". Podemos colegir también que la apreciación por parte de la crítica del tono humorístico en la obra de Vilas no es privativa de un género, sino que se da de igual manera en sus obras en prosa -relato o novela- y en su poesía. Bien es cierto que cualitativamente la interpretación de la modalidad del humor sí parece variar, siendo señalada de forma más clara en su obra lírica la ironía como recurso para una nueva tipología de poesía social.

\footnotetext{
${ }^{3}$ Para más ejemplos de la recepción humorística vid. Miñana (2008), Company (2008), Calvo (2009: 92), Fontana (2009), Marzal (2009), Miranda (2010), Marías (2013) o F. A. Moreno (2014).
} 
Más allá de la revisión cronológica y genérica, lo que nos muestra una vista general de las críticas es que no todos los lectores o críticos aprecian igual el humor en las obras de Vilas. Ya hemos dicho que hay quienes no lo mencionan, pero hay también quien plantea sus dudas, como hemos visto en la cita de Antonio J. Rodríguez (2009: 96). Hay incluso autores que niegan directamente que la obra vilasiana les mueva a risa, como hace Javier Calvo con ocasión de la inclusión de un relato de Manuel Vilas en una antología de "Clásicos del humor":

\begin{abstract}
A mí Manuel Vilas no me parece en absoluto un humorista. Es más: yo no me río con sus libros. No me hacen gracia. [...] Vilas me parece algo muy serio. Su literatura me fascina y me sobrecoge. Relatos como el fabuloso "Selene trips" me parecen artefactos terribles hechos con la materia de los sueños y me plantean cuestiones terribles sobre la muerte de la conciencia histórica y la idea de que el origen mismo de la cultura humana lleva incluido su final. Debo de ser el único que lee así a Vilas, o por lo menos estoy en minoría frente a quienes lo consideran irresistiblemente divertido. Yo lo considero irresistible, eso está claro. Pero [...] no me hace ninguna gracia. Ninguna gracia. (Calvo 2010)
\end{abstract}

Lecturas como esta deberían hacernos plantear el humor desde sus bases, abordar la risa desde un plano general que explique por qué Calvo no se ríe con la obra vilasiana, y por qué entre quienes sí ven humor en ella, este sea, según hemos visto, absurdo para unos, para otros festivo, para algunos negro, o sardónico, o mordaz, para otros irónico, satírico o paródico, para unos cuantos crítico, tragicómico, lúdico, y para otros grotesco, o incluso somarda.

\title{
2. PRECISIÓN TERMINOLÓGICA
}

Antes de adentrarnos en teorías sobre el humor, quizá convenga indagar, al menos para asegurarnos de que no supone un obstáculo o un punto de desencuentro o malentendido, en una mínima precisión terminológica en torno al asunto del humor y sus aledaños. Como bien explica Carmen Bobes, el término "humor" proviene de la medicina antigua, de la época hipocrática. Se toma de la teoría humoral, que hasta el siglo xIx trataba de explicar, mediante cuatro humores o líquidos presentes en el cuerpo humano, los diferentes tipos de personalidad (temperamentos) y ciertas enfermedades o condiciones y estados humanos por la prevalencia o armonía de estos en el individuo. Este humor antiguo, entendido como líquido que segrega el cuerpo, parece no tener que ver con nuestra concepción del humor, pero si observamos la teoría de los temperamentos vemos que la relación del humor antiguo y el actual con la actitud personal mantiene cierta línea de continuidad. La persona que adolecía de exceso de bilis negra, uno de los cuatro humores, era la considerada melancólica, y esta cualidad de la melancolía viene asociándose con la locura y, con ella, con la risa, a través de la figura de Demócrito de Abdera, desde la Antigüedad. Esta risa relacionada con uno de los humores, democrítea, melancólica, generalmente funcionando en oposición al Ilanto de su complementario, Heráclito, es una risa no vinculada con lo cómico, sino más bien tragicómica, una risa irónica ante los 
males y el absurdo del mundo ${ }^{4}$, y que en parte tenía relación con los caracteres que "habitaban" lo literario (vid. Bobes 2010: 26-27).

El término humor aparece en el DRAE desde su primera edición, sin embargo humorístico, humorista y humorismo no aparecen hasta 1914, como observó con agudeza Carmen Bobes. El humorismo se define en las ediciones del DRAE desde 1914 a 1970 como "estilo literario en el que se hermana la gracia con la alegría y lo alegre con lo triste", y en 1984 y 1992 como "manera de enjuiciar, afrontar y comentar las situaciones con cierto distanciamiento ingenioso, burlón $y$, aunque sea en apariencia, ligero. Linda a veces con la comicidad, la mordacidad y la ironía, sin que se confunda con ellas; y puede manifestarse en la conversación, en la literatura y en todas las formas de comunicación y de expresión" (vid. Bobes 2010: 28). Lo que podemos inferir de estas definiciones, al menos, es la delimitación conceptual clara entre el humorismo y la comicidad: aunque sean conceptos limítrofes, el humor actual parece derivarse de la tensión entre lo trágico y lo cómico, según señala la definición original y apuntalan algunos estudiosos, como Celestino Fernández de la Vega (vid. Buceta et al. 2014: 4). Puede entenderse si pensamos que "lo cómico concibe únicamente la hilaridad como fin, esto es, nace de una situación jocosa en la que no existen elementos trágicos que puedan generar dicha tensión" (3). Lo cómico, por tanto, parece basar la risa en la condición de superioridad respecto a lo considerado ridículo, que desde Platón, Aristóteles y más exhaustivamente Cicerón y después Quintiliano, se define como una fealdad moral o una deformidad física que es resaltada de una manera no fea en sí misma (Paraíso 2002: 74). El grado de agresividad sobre lo considerado risible es lo que marca la diferencia entre la mordacidad para satirizar o la alegría del chiste (la dicacitas y la facetia, para Cicerón), pero el factor común en la visión de lo ridículo en lo cómico es la crueldad. Cuando esta es ejercida desde la comicidad irónica el resultado es el sarcasmo, que se distancia de la ironía por esta cuestión de grado, como explica Carmen Bobes:

La ironía [...] es un recurso ingenioso para afirmar o sugerir lo contrario de lo que se dice con las palabras; esta es fundamental en la literatura de humor y se relaciona con la sátira y el sarcasmo. El sarcasmo es la ironía llevada a un grado extremo de dureza. El sarcasmo es término de origen griego que significa mofa, escarnio, broma; frente al humor y la ironía, el sarcasmo incluye crueldad y ensañamiento, y suele dirigirse, según la Retórica, contra personas indefensas. (Bobes 2010: 29)

La ironía es, según los términos de Gadamer, un tipo de "antitexto", es decir, "cualquier tipo de chiste o gracia que da a entender lo contrario a su sentido literal" (apud Bobes 2010: 29)5 ${ }^{5}$, que consiste en querer significar lo contrario

\footnotetext{
${ }^{4}$ Adelantando lo que expondremos más adelante, podemos ver en Vilas la figura del riente y melancólico Demócrito, por su risa aparentemente alocada pero honda y por su poética basada en la huida del aburrimiento (vid. Vilas 2014a: 44, 52, 130-131, 255): "El personaje de Vilas es la reencarnación moderna de Demócrito de Abdera. Los locos son los cuarenta millones" (Beltrán 2009: 35).

${ }^{5}$ La ironía, no obstante, no tiene que estar imperativamente unida al humor. Hay autores como
} 
o algo distinto de lo que se está diciendo. La eironeia para Platón y Aristóteles equivale a disimulo; el ironista - eiron- es un disimulador que finge saber menos de lo que sabe, es lo contrario al alazon, el fanfarrón (Ballart 1994: 40 y 44). Como hemos visto la ironía llevada a su extremo más cruel es el sarcasmo, que es el que aparece en la sátira, donde el elemento esencial es el distanciamiento del objeto risible. La sátira tiene también relación con la parodia. Si ambas ofrecen la relación entre un hipotexto y un hipertexto, en términos genettianos, la diferencia está en el régimen con la que lo hace cada una: la sátira es crítica, de ahí el distanciamiento, y la parodia es lúdica; una focaliza su atención en los valores sociales y la otra en las formas de los textos en relación, como explica con claridad Juan Carlos Pueo (2002: 54 y 57).

Frente al componente de crueldad o superioridad respecto a lo risible de lo cómico, el humorismo, al menos en las teorías del humor moderno, como resalta Carmen Bobes, desecha la crueldad, y ríe más bien desde la comprensión, la ternura o la compasión (en esto coinciden Thackeray, Miguel Mihura o Fernández Flórez, según señala la estudiosa). Así, la comprensión es el rasgo distintivo del humorismo moderno respecto a lo cómico, la distancia entre reírse con y reírse de (vid. Pueo 2002: 51-52).

Puede que sea la conciencia de lo trágico en su tensión con lo cómico, o la misma voluntad de trascendencia y visión del mundo que a veces se le ha querido negar al humor la fuente de esta mirada comprensiva del humorismo. Por este camino, el humor actual está llegando a lo que, aplicado al cine y el cómic, se ha llamado post-humor, que como expone Jordi Costa (2010: 10) va más allá de la posición de no crueldad frente a lo risible haciendo un humor que constata su propio fracaso, cuyo objetivo fundamental ya no es ser gracioso o hacer reír, la carcajada (recordemos aquello de que "lo cómico concibe únicamente la hilaridad como fin" [Buceta et al. 2014: 3]), sino llegar al camino de lo serio en un proceso que con la no conclusión de sus mecanismos humorísticos consiga otros efectos sorprendentes en el lector o espectador. Como explica Costa (2010: 10) a partir de las historietas explicativas de Darío Adanti, podemos ver "el post-humor como el fracaso de los propios mecanismos de la comedia. Es decir, la comedia no siempre es una comicidad que triunfa [...] sino, también, una comicidad que fracasa... aunque de forma sorprendente e inesperada". La risa del humor en su forma más actual, si la hay, es una risa ambivalente, que vuelve, en realidad, al centro del humorismo, esa tensión entre la risa y el llanto, lo cómico y lo serio, que está indefectiblemente unida a otras respuestas y reacciones enfrentadas, que es, en última instancia, ambigua y en cierta medida incómoda, como el post-humor explicado por Jordi Costa. Así, calificamos la obra de Vilas como "humorística", encuadrada en el humorismo o el post-humor.

\section{HACIA UNA TEORÍA DE LA RISA}

Teniendo en cuenta estas apreciaciones terminológicas y una vez clara su delimitación, vamos a tratar de centrarnos en las preguntas previas a cualquier

Northrop Frye que insinúan que son incluso nociones excluyentes (vid. Ballart 1994: 168). 
análisis: por qué o de qué nos reímos. Estas preguntas se han contestado desde posturas esencialistas sobre el humor, desde teorías psicologistas, psicoanalíticas, contextuales, etc. (ver páginas siguientes). Vamos a tratar de esbozar algunos elementos generales, intentando conducirnos hacia una explicación integral que relacione todo el racimo temático que observamos en el compendio crítico sobre Vilas, en la medida en que esto sea posible.

Durante un gran periodo de tiempo la teoría sobre lo cómico fue un castillo en el aire, en el sentido de que estuvo sustentada en una obra desaparecida: la segunda parte de la Poética de Aristóteles. La tradición que seguía al estagirita trató de recomponer la teoría aristotélica de la comedia con la raíz de los pequeños fragmentos que tenía y la emisión de hipótesis basada en el método de la simetría con la teoría de la tragedia desplegada en la Poética. El Tractatus Coislinianus, manuscrito anónimo del s.x, recoge parte de esa tradición cómica aristotélica, y en el Renacimiento muchos fueron los tratados sobre la risa y el humor que siguieron las ideas de escoliastas y comentaristas de la Poética (Bobes 2010: 16-19). La aparición y publicación del Coislinianus hizo que algunos estudiosos hicieran un intento de reconstrucción de la teoría de ese segundo libro de Aristóteles sobre la comedia, como es el caso de Lane Cooper (Holland 1991: 89) o el del neoaristotélico de Chicago Elder Olson. Es, asimismo, interesante en la obra de Olson su clasificación de las teorías del humor entre las que tienen en cuenta el objeto del que nos reímos, las que buscan la causa de la risa en la persona que se ríe, sea en su mente o en su cuerpo, y por último las que explican la risa por la relación entre el sujeto que ríe y el objeto del que se ríe (1978: 16-17).

La agrupación de las teorías del humor de Elder Olson en estos tres bloques es sin duda útil, pero quizá no recoja todo el espectro que históricamente se ha presentado. Por eso vamos a recurrir al esquema que propone Norman $\mathrm{N}$. Holland antes de promulgar su propia teoría del humor basada en la recreación de la identidad:

Theories of humor: Why do people laugh?

I. Stimulus: incongruity

a. Cognitive: simultaneous affirmation and negation

b. Ethical: between things as they are and as they ought to be

c. Formal: between content and form

II. Conditions

a. Playfulness

b. Suddenness

III. Psychology

a. Archetype theories

b. Psychologies of consciousness

i. Relief theories

ii. Superiority theories

c. Psychoanalytic theories

d. Experiments

IV. Physiology

a. Laughter as innate action cluster 


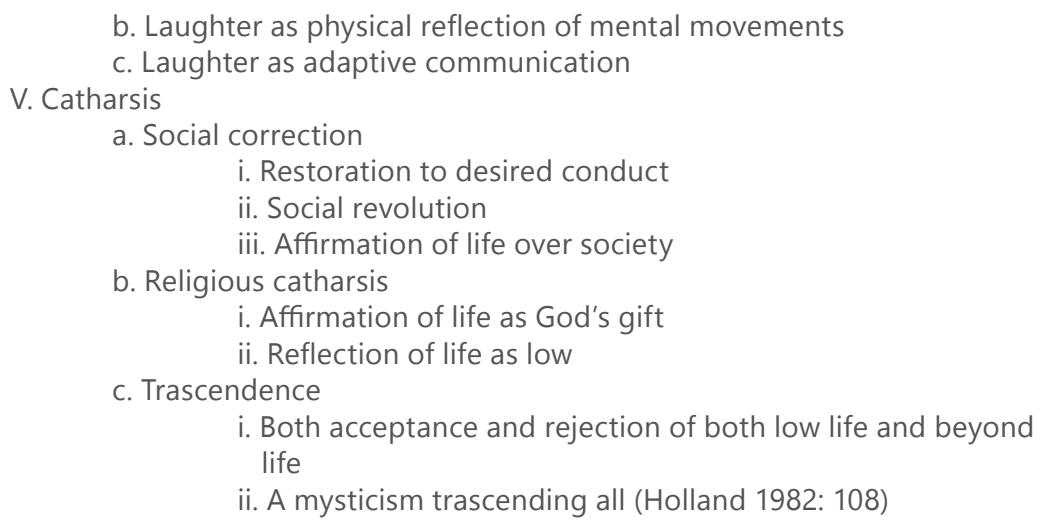

Como se puede observar, hay puntos comunes en las teorías de Olson y Holland. Las diferentes teorías no tienen por qué ser excluyentes, sino que sus presupuestos pueden entenderse como una serie de condiciones mínimas necesarias, una serie no definida de antemano, sino diferente para cada sujeto y ocasión. A la hora de reflexionar sobre la teoría de la risa que es más aplicable a la literatura de Manuel Vilas hay que buscar, en consecuencia, la más abarcadora, pero habrá otras que necesariamente ayuden a completar el espectro de las diferentes lecturas potenciales. Probablemente con las teorías de la incongruencia del estímulo podríamos explicar muchas de las risas que produce la literatura de Vilas. También las teorías de las condiciones son necesarias: la risa no se producirá si no se conocen o no se entienden las referencias que forman parte de la situación risible, y la literatura de Manuel Vilas es un constante desfile de personajes y circunstancias tomados de la realidad, muchos de ellos de la española, tanto culta como popular. Vilas, consciente de esta condición sine qua non para la comprensión de su literatura, lo utiliza como un nuevo recurso humorístico, introduciendo en algunas de sus obras notas explicativas a pie de página sobre los personajes reales que aparecen en su novela. El humor basado en la conciencia de las condiciones para que se dé la risa en la interpretación de su novela se realiza de dos maneras: por un lado haciendo explícita su conciencia del problema de traducibilidad y hermenéutico de sus referencias, "Por si España se traduce" (2008: 68, n. 2; 121, n. 8; 179, n. 14; 219, n. 32) o "Para la traducción de España (2008: 117, n. 6), o en notas donde la explicitación va unida a ideas disparatadas (y por tanto marcando la ironía). Por otro lado, introduce notas rigurosas en su contenido (que aún así pueden resultar humorísticas por la falta de necesidad de ciertas explicaciones para sus lectores modelos o medios, una manera de disimulo ingenuo -ironía- o de parodia de otros libros cuyas notas son excesivas e innecesarias), con notas que tienen el aspecto de explicativas pero cuyo contenido es ostensible y manifiestamente falso.

Estas teorías son, como vemos, eficaces para entender la fuente y el contexto de la risa en determinados momentos. Vamos a proponer, no obstante, para la obra de Manuel Vilas, la aplicación de una teoría más abarcadora, que está a medio camino entre las teorías de los arquetipos de la clasificación de 
Holland (III.a), por su carácter antropológico, algunas teorías de la catarsis (v.a), y algunas teorías psicoanalíticas (III.C).

Hace tiempo que algunos investigadores, con M. Bajtín a la cabeza desde los años 30 -pero sobre todo a partir de finales de los 60 con el impulso que reciben las ideas del pensador ruso en Europa gracias a Kristeva ${ }^{6}$-, han señalado que hay cierto tipo de risa en el ser humano que está relacionada con la cultura y la fiesta popular. Esta vinculación es innata, se da en todas las culturas y tiempos y tiene que ver con los universales humanos, con fuertes lazos con otros instintos básicos e ideas arquetípicas como la fertilidad y unida a ella los ciclos de muerte y renacimiento. Ya Aristóteles expresó la capacidad privativa del hombre de reírse, y el carácter natural de la risa en su condición de ser humano (Le Goff 1999: 44), y es aquí donde se cristaliza: en estas fiestas populares de carácter especial por la relación con la fertilidad -ligada a la naturaleza o a la sexualidad-, con la compleción de las necesidades fisiológicas y antropológicas básicas, con la conciencia de la muerte y la regeneración de la vida (el eterno retorno del ciclo de las estaciones), con la liberación del componente más animal o salvaje del hombre. La fiesta popular es donde el hombre puede dar rienda suelta a su naturaleza de homo ridens, liberar y poner en práctica una cosmovisión habitualmente vedada. Por eso estas fiestas convierten en ritual el banquete, lo carnal, el cambio de roles personales, comunitarios y estamentales, la ruptura de las normas y el orden social, y por eso, por su carácter primigenio, connatural, es la primera plasmación social, compartida, de esa capacidad que Aristóteles veía en nosotros. Este componente universal explicaría por qué hasta en los ambientes y en las épocas donde la risa era más aborrecida y rechazada, incluso prohibida y castigada, como en la vida monacal medieval, surgían géneros literarios netamente humorísticos relacionados con estos elementos festivos, como la joca monacorum (Le Goff 1999: 51).

Esta risa antigua, festiva, en el paso entre lo antropológico y lo literario, es la que parece haber dado origen a la comedia como género, que comenzó en ciertos lugares con ocasión de este tipo de celebración (Bevis 2003: 8). En el inicio de nuestra cultura occidental, las fiestas dionisiacas, los banquetes, las saturnales, eran los momentos donde el humor estaba permitido sin restricción, donde era lícito todo aquello censurado en la vida corriente. Se puede decir que en el banquete y la fiesta hay una parodia de las instituciones políticas y religiosas, que llevada a la literatura se convierte en licencia cómica. La tradición cómica antigua es la traslación a lo literario de esta risa antigua, que es, desde su raíz, igualitarista, anti jerárquica y utópica, y cuya fuente es la percepción del escándalo de la desigualdad (Beltrán 2002: 208).

Existe, sin embargo, la idea, que comparten varios autores (Elmer Edgar Stoll, Albert Cook y Ortega y Gasset, entre otros [vid. Cutler 1986: 29]), de que los géneros humorísticos no son subversivos por su carácter igualitario, sino, al contrario, conservadores del statu quo. Esta concepción se entiende desde el punto

\footnotetext{
${ }^{6}$ Vid. Bubnova (2000) para una visión completa de la recepción y expansión de la teoría de la cultura popular de la risa y el carnaval.
} 
de vista de que son los poderes e instituciones gobernantes quienes permiten y regulan en tiempos y formas la subversión contra sí mismos, quienes establecen la fiesta del igualitarismo como ficción controlada con fecha de caducidad, que sirve de válvula de escape permitiendo el equilibrio y el control social el resto del ciclo temporal entre fiestas. Como explica Scott Cutler Shershow:

... [i]n Saturnalian festivity, the human community both distorts and reaffirms the social facts of its life, allowing a temporary period of anarchy which serves as an ironic confirmation of law and order. On the stage, similarly, we ridicule the figures of authority and deny, for the moment, the real relations of power and submission that structure our lives, but we do so with the unspoken acknowledgment that the stage is not the world, that holidays and plays alike must end. (Shershow 1986: 16)

Esta doble visión de lo cómico como subversivo o conservador del orden social se entiende observando la historia no homogénea de los géneros literarios de la risa. Luis Beltrán traza esta historia, explicando que existió una risa antigua, la gran risa, que es transgresora, libre e igualitaria, y nos lleva al pensamiento utópico, aquella de la que hemos hablado con anterioridad, y otra risa menor, relacionada con otros géneros, donde el pensamiento de la risa está debilitado y se ha vuelto pragmático, antiutópico, se ha desnaturalizado y ha convertido la risa en reprobatoria (2002: 210). La filosofía de la risa ha mantenido en autores y momentos concretos su vitalidad, no llegando nunca a desaparecer y mostrándose igual de crítica en el Renacimiento con Erasmo, Joubert o Rabelais, con un auge en el primer Romanticismo y reviviendo en Bajtín (Beltrán 2002: 212 y 255).

\section{LA RISA VILASIANA}

Teniendo en cuenta esta división, vamos a argumentar que la literatura de Manuel Vilas a la que nos referimos es una forma de recuperación contemporánea de la risa antigua, una concreción actual de la gran risa. Mostraremos, para ello, las ideas que el propio autor expone sobre su obra, su poética, los conceptos que ha señalado la crítica y los elementos de su obra que ejemplifican esta reactualización de la literatura proveniente de la fiesta popular y del banquete.

Comencemos con una afirmación de Javier Calvo, aquel autor que declaraba no reírse con la obra de Vilas, no encontrarla graciosa, que nos obligaba a asumir una visión del humor del autor desde la recepción: "Fundamentalmente [...] se trata de un autor cómico, no solamente por sus famosas bromas, sino por el tratamiento gozoso, casi triunfal, de todas las ausencias de resolución ideológica que fundamentan su discurso" (2009: 94). Esta visión nos aleja de las teorías sobre el estímulo risible, de las incongruencias como motivo de la risa en Vilas, y nos acerca a ese otro punto central que habíamos señalado al inicio entre los conceptos repetidos por la crítica: el vitalismo, expresado generalmente a través de lo carnal, de un materialismo exacerbado. La literatura de Vilas es eminentemente humorística, pero en un sentido que va más allá de lo lúdico, del gag, de la broma, asentándose más bien en lo festivo como postura vital, como cosmo- 
visión (así lo señala buena parte de la crítica. Vid. Espigado 2009: 16; Marqués 2008: 108; Rodríguez 2008; Company 2008).

El propio Vilas parece tener clara su poética festiva, que ha expresado con contundencia en numerosas ocasiones: "La literatura que me gusta estaría en esa estela, en la estela de la festividad coital" (2014a: 129), o bien "quise que Aire Nuestro fuese una fiesta. No quise ninguna ley. Quise escribir con una libertad peligrosa" (2014a: 130), o "el gran día de fiesta que estalla en los corazones y mata toda construcción humana que no dé placer carnal. Allí está mi novela, en esa fiesta. El maravilloso carnaval, el travestismo glorioso, el afán de tocar cuerpos, el afán de luz y de muerte de la responsabilidad" (2014a: 131).

El humor en Vilas no es un asunto retórico, es una cosmovisión: su literatura sería así realista, expresión de un mundo que ve como disparatado en sí mismo: "yo no creo que la vida vaya en serio, yo creo que la vida es una broma infinita", dice Vilas utilizando la doble expresión intertextual de Gil de Biedma y Wallace (2014a: 111). Es, por tanto, un planteamiento desde el que cuestionarse el mundo, hacer literatura, decir en clave festiva, porque según defiende Vilas "sin humor no se puede hablar de nada. Y el humor empieza por uno mismo siempre" (2014a: 26). Aquí presenciamos la relación con otro de los elementos temáticos que encontrábamos al inicio en la revisión crítica: la autoficción tan característica en Vilas, que está unida al humor a través de la autoparodia ${ }^{7}$ y el autoensalzamiento irónico. En todas sus obras humorísticas aparece la autoficción de una u otra manera: puede aparecer directamente Manuel Vilas, en primera persona o en tercera, acercándose al escritor y la persona que realmente es (2008: 81; 2009: 202 o 2012b: 38, por ejemplo); puede estar presente adjudicándole su nombre al de otra persona identificable, como en la usurpación que vemos en la muerte de Miguel Ángel Blanco narrada en España (2008: 99); puede introducirse como paranarrador (2009: 121); puede aparecer a través de elementos reales de su vida que lo identifican, como su perro Golo en Zeta, en Magia o en Los inmortales, con un informe de deficiencias de su piso o una foto suya (2008: 131), mediante una resonancia magnética de la zona lumbar que precede a una conversación con sus propios huesos (2012b: 111 y ss., también en 2013: 38-9), a través de su padre, del mismo nombre, incluyendo incluso su foto o una carta suya tras leer después de muerto las obras donde su hijo le incluye (2008: 139; 2009: 190, 249-50); o puede aparecer en la narración su propia muerte (2009: 134), su esquela (2009: 222), e incluso su resurrección por parte de un vampiro resucitador (2008: 218). Puede presentarse también con su nombre transmutado en muy diferentes variaciones, siguiendo la idea de la multiplicación de identidades y la difuminación del yo por omnipresencia y mutación

\footnotetext{
${ }^{7}$ Explicaba ya Quintiliano que cuando la risa versa sobre el sujeto que habla (y Vilas juega siempre con la ficción de que es él el sujeto que habla, mostrando a la vez que "él" es un constructo configurado literariamente) esa autoagresividad es irónica, falsa (Paraíso 2001: 279). Vilas es en ese sentido un eiron, un gran disimulador que se finge ingenuo o ignorante, que a veces se presenta irónicamente como alazon en esa construcción de "Gran Vilas" o "San Vilas", por ejemplo (vid. sobre todo Vilas 2012a). Por otro lado, podemos anticipar que la autoparodia es una de las características de la sátira menipea: "penchant for self-mockery and self-defeat" (Freudenburg 2005: 20).
} 
expandida tan característica en él: Lenin Vidal (2004: 74), Mario Vidal, Manuel del Val y Emeuve (2004: 113), Manel Vila-Zavala (2008: 179), Friedrich Witold Wilâz (2008: 205), Manuela Vilas (2009: 44), Bobby Vilas (2009: 84), John Vidal (2009: 150), Richard Vilas (2009: 176), César Vilas (2009: 180), Aristo Willas (2012b: 15), o Maximiliano Vilas (2012b: 195).

Este reírse de sí mismo le sitúa en la tradición humorística en la que le gusta insertarse ("En realidad lo que soy es un humorista, pero fiel finalmente a Cervantes" [Caballero 2009]), la que uniría a Kafka y Cervantes. Seguir las huellas de esta tradición, al menos de cómo él la concibe, nos ayuda a situar con claridad el humor vilasiano en la corriente de la filosofía de la risa, proveniente de esa risa antigua, subversiva. Sobre Cervantes dice Vilas que era "el aroma de la calle, el aroma del polígono industrial, una mezcla de dicha, júbilo, orgía y risa" (2014a: 40), y sobre ambos dice, desvelando mucho de su propia manera de entender el humor:

De quien está cerca Kafka es de Cervantes, con quien comparte la idea fundamental de la redención del hombre a través de un poético y misterioso sentido del humor. La risa lenta, silenciosa, carente de mal, auspiciada por una complicada maquinaria de la que desciende el enigma de la identidad, una risa que se vierte sobre los confines más graves de la conciencia, así es el humor de que hablo, un humor lleno de nieve, un humor helado. (Vilas 2014a: 90)

Vemos su fijación por Kafka desde las primeras obras humorísticas, en su tratamiento como personaje (en Zeta Kafka aparece viviendo en Teruel [2002: 19-20], vuelve a aparecer como "Franz" en la parte inicial de Magia), como en el discurso directo sobre él en España: "Kafka es el luto. Pero también es el luto cómico, y es la gran comedia del viejo pleito entre los hombres y los dioses" (2008: 124). La tematización de la unión de la tradición kafkiana y la cervantina se da en Los inmortales, con la conversación entre Cervantes y Kafka en el sanatorio de Kierling en 1924 (2012b: 101 y ss.). Es en esta obra donde se hace más explícito el homenaje y el seguimiento de Cervantes, con el recurso del manuscrito encontrado que estructura la obra y la aparición de uno de los protagonistas, Miguel Saavedra, que es la figura que vertebra casi toda la novela en sus viajes en espacio y tiempo.

Ese mismo es, más allá de las bromas, el humor de Vilas, un humor trascendente, que no siempre resulta gracioso, o que, siéndolo, produce a la vez otras reacciones y reflexiones, o una risa ambivalente, como el post-humor del que hablábamos antes, cuya finalidad última no era entretener mediante la carcajada lúdica. Preguntado recientemente por la trascendencia del humor, y continuando con su casi obsesión cervantina dice Vilas en una entrevista:

CAVIEDES: Cuando a algo se le da una trascendencia a veces olvidamos que el humor también puede tenerla.

VILAS: Sobre todo en España, que es el país que inventó el humor moderno a través de Cervantes. El gran humorista de todos los tiempos es Cervantes, el primer humorista moderno, inteligente, de humor fino que pone en cuestión 
la autoridad y de humor de calado político y filosófico. En tanto en cuanto el humor de Cervantes hace dudar de la realidad, y eso es cuestionar el mundo, y cuestionar el mundo es cuestionar la autoridad, así que tiene una vocación política. (Caviedes 2014)

Sonia Gómez (2010) ha relacionado el humor vilasiano con el de Enrique Jardiel Poncela, y Javier Calvo y Alberto Olmos, con buenas razones ${ }^{8}$, con el de Antonio Orejudo. Más allá de su singularidad, tan especial, él mismo se une en el carácter festivo a otros escritores que cohabitan en el campo literario español: "hay algo festivo en todo derrumbamiento. Yo en muchos de estos libros veo festividad [...], al menos en los de Orejudo, Mallo, Sebastián, Marzal y Reig" (2014a: 157). Su particular vitalismo y sentido festivo-trascendental le une, sin embargo, más directamente con ese Cervantes político, cuestionador, anti-autoritario, en la línea de la filosofía de la risa, de la gran risa antigua que se fue debilitando pero manteniéndose viva en el humanismo, en Rabelais, en Cervantes, en Valle-Inclán ${ }^{9}$, ahora en Vilas. Esta característica de su humor, creemos, es la que ha hecho que una buena parte de la crítica, como dijimos al inicio mostrando los agrupamientos temáticos de la recepción, clasificara la obra de Vilas como política. Algunos críticos, de manera más prudente y atinada, según creemos, han cuestionado la rotundidad de este carácter político o de crítica social y han planteado su ambigüedad ideológica (Espigado 2009: 17; Calles 2009: 230 y 622 y ss.; A. J. Rodríguez 2009: 96). El humor tiene la característica de ser un elemento interpretable, que rara vez está marcado explícitamente o se muestran indicios irrefutables de él en el texto mismo. La crítica o la apología de un elemento dependen en última instancia de si vemos o no ironía o humor en la parte "no escrita" del enunciado, y, al igual que le ocurre a Juan Carlos Pueo con la parodia (2002: 107-108), tampoco en el humor vemos posible una aplicación de las ironías estables que propone Wayne Booth -puestas en entredicho por ciertos autores, como Stanley Fish, por otro lado-, de manera que o bien el humor está convocado de manera muy clara (en cuyo caso podríamos plantearnos incluso si hay humor ya en esa explicitación tan obvia ${ }^{10}$ ), o toda crítica donde interceda el humor no podrá dejar de ser ambigua. En el caso de Vilas, si aplicamos la lectura humorística a su ensalzamiento del capitalismo o del McDonald's en el conocido poema de Resurrección (2010: 105-107), debemos ser suspicaces de la misma manera con las ironías referentes a sus afirmaciones críticas o buscar la clave hermenéutica para entender lo celebratorio aplicado a Belén Esteban o Chikilicuatre (Vilas 2014a: 40-41). Para nosotros el carácter político en la obra de

\footnotetext{
8 "Por su elogio del carnaval, el humor y la inmundicia solamente se me ocurre compararlo con Antonio Orejudo" (Calvo 2009: 95); "La pasión por la literatura española, muy especialmente la de la generación del 27, conecta la narrativa de Vilas con otro escritor estupendo: Antonio Orejudo. Ambos parten de esa tradición escolar y la llevan a lo grotesco" (Olmos 2009).

${ }^{9}$ Dice Vilas en un momento de España: "Valle Inclán creyó que España era el infierno cómico que Dante no supo escribir" (2008: 119).

10 También se puede dar el caso contrario, la negación explícita como recurso humorístico: "Antonio Alcántara es el mejor de los hombres, no hay ironía, lo digo tal como lo pienso" (Vilas 2013: 17).
} 
Vilas solo puede entenderse desde la lógica de la inversión de su marcada risa ambivalente: es político como lo eran las obras cómicas asociadas a las fiestas primitivas, como pueden serlo los textos pantagruélicos, por la libertad de su expresionismo materialista y carnal, por la elección de un humor incómodo, por su libertad en el decir, que está contra lo políticamente correcto. Así es "política" la risa antigua: siendo ambigua, tragicómica, haciéndonos dudar de todos los presupuestos fijos de lo humano, de todo lo asentado, del orden social y de la autoridad, formando así una nueva visión del mundo. Es un humor, por tanto, crítico contra todo, que de todo se ríe, incluso de la voz crítica (de ahí la ambigüedad ideológica), donde sobre todo impera la libertad; en ese sentido es política la obra humorística vilasiana. Esta libertad comienza en la hibridación de géneros y el libre etiquetado genérico de sus obras, que es otro de los grandes asuntos temáticos tratados por la crítica (Cilleruelo 2006, Mora 2008, Reig 2010, Gómez Trueba 2013), y que solo se puede entender también desde la visión omniabarcadora del humor vilasiano.

Recordando la delimitación terminológica del inicio, la obra vilasiana no sería cómica, por la falta de crueldad, sino humorística: no señala a quien se sale de la norma, al socialmente ortodoxo como elemento ridículo a reprobar, sino que promueve la libertad individual y se ríe, en cambio, de las convenciones sociales, lo establecido, los valores en los que se sustenta la sociedad. La risa que pretende despertar no es, por tanto, inofensiva (el epílogo de su reciente recopilación de artículos se titula "Si respeto, me aburro" [2014a: 253]), o meramente lúdica, sino, como la risa primigenia, subversiva. Como explica Rosa Benéitez, es un humor donde lo importante es

... la inversión, el apelar a la otra cara de los acontecimientos, la imaginación que trabaja a partir de una postura radicalmente irónica. El recurso temático a ciertos hechos o prácticas propios de la cultura contemporánea no supone aquí la asunción y celebración del statu quo, sino todo lo contrario, una crítica perversa (en el mejor sentido de la palabra) a lo establecido y al orden impuesto. (Benéitez 2009b)

El propio Vilas comparte también esta idea de la crítica desde el distanciamiento, la desacralización: "El humor es amor, también. Es una forma de crítica contra la autoridad. Cuestiona la autoridad. Nos hace más libre. Nos quita solemnidad, esa pátina de tragedia que tiene la vida humana" (Rocamora 2012). El humor, por tanto, expresado como un divertimento muy serio, como una importante fiesta donde es obligatorio participar pero donde la risa es voluntaria:

\footnotetext{
... es que mi novela [Aire nuestro] no es satírica ni crítica ni nada de eso, es sobre todo festiva. Y yo me sumo como personaje a la celebración. Por otro lado está la libertad de ser varias personas en un texto literario, de vivir vidas que de otra forma no podrías vivir. La base está en mi afán de buscar la plenitud del humano, que significa fiesta y divertimento. Hacer cosas que no están permitidas, como el travestismo. (Caballero 2009)
} 
También sobre la consciente ambigüedad que sustituye la risa inofensiva, el inicio de Los inmortales, el prólogo firmado por Aristo Willas, comienza hablando de "[l]a edad de la comedia y de la risa destructiva" (2012b: 10), y señalando que "la risa y la ambigüedad, la comedia y la banalidad, ese es el vacío de estas páginas" (2012b: 13).

\section{RISA CARNAVALESCA}

Podríamos explicar esta risa de Vilas -celebratoria, festiva, ambivalente- desde la perspectiva de la filosofía nietzscheana. El propio creador explica en una entrevista que "la poética fundamental es una afirmación de la vida, en términos nietzscheanos sería un sí a la vida enorme en donde no hay límites" (2014b), y no es casualidad que el primer verso del primer poema de El Cielo, el poemario que consideramos la primera obra de este Vilas, sea un yo poético que habla a un tú que es Nietzsche, diciéndole "mira tu sí a la vida aquí reunido" (2010: 145). Algunas teorías psicoanalíticas de la risa, como la de Charles Mauron en Psicocrítica del género cómico, la teoría de la inversión, también ayudarían a entender la continuidad en las obras humorísticas distantes de ciertos elementos recurrentes, por la necesidad, en la línea de lo visto previamente en la risa antigua, de revertir el orden social dominante a través de la construcción de su reverso cómico en lo literario; así, lo habitualmente valorado es ridiculizado, y ensalzado lo que por lo común está poco considerado (Hernández 2010: 51). Es sin embargo, como se habrá venido intuyendo, la teoría de Mijail Bajtín sobre el carnaval y la carnavalización, con su mundo al revés (monde à l'envers), la que más se ajusta a la literatura humorística de Vilas. Él mismo lo expresa en múltiples ocasiones en estos mismos términos, refiriéndose a varias de sus obras (Vilas 2014a; Caballero 2009; Rocamora 2012). La crítica también ha apuntado el elemento carnavalesco, señalando a diferentes obras (Moreno 2008; Ferré 2012; A. J. Rodríguez 2009: 97; Pozuelo 2009) y dejando clara la vinculación bajtiniana del carnaval al que aluden (Moreno 2008; Serrano 2012: 414). Las alusiones al carnaval hacen referencia a la alocada ficcionalización (Calvo 2009: 93) y la fabulación hasta el paroxismo, sobre todo de los personajes tomados de la "vida real" (Olmos 2009). Las características del carnaval tal y como lo entiende Bajtín son aplicables a la obra humorística de Vilas no de forma parcial o para ciertos elementos, sino desde sus raíces y su entender la risa como cosmovisión. Se basa en el principio de la inversión -resaltando todo lo material y lo bajo, rebajando todo lo institucionalizado o divinizado, sacralizando y desacralizando, haciendo un reverso del mundo-, tiene el elemento de juego del que habla Bajtín (1989: 12), la estructura de las leyes que rigen sus mundos ficcionales sólo funcionan desde las leyes de la libertad, el abandono de tabúes y la liberación transitoria en lo que dura la ficción, aplicado esto a géneros, formas, temas y personajes. Supone, ante todo, una "vida festiva" donde prima lo popular (Bajtín 1989: 14) y se caracteriza, por tanto, por un humor carnavalesco, que "es ante todo, un humor festivo" (Bajtín 1989: 17). Pertenece, por lo tanto, a la corriente de la risa festiva popular, alejada de la sátira moderna, en tanto en cuanto la risa de Vilas 
lo abarca todo, es inclusiva a través de la autoficción, y no hace uso de la reprobación desde un exterior inmune; cumple con la gran risa de la que hablaba Luis Beltrán, que es la misma que esta risa popular, a la que Vilas da continuidad, y que explica Bajtín: "la risa popular ambivalente expresa una opinión sobre un mundo en plena evolución en el que están incluidos los que ríen" (1989: 17).

Temáticamente recurre constantemente a lo popular, que en este caso actual tiene que ver con la cultura pop y del espectáculo, en un equilibrio constante entre la alta y la baja cultura, incluso en su indiferenciación ("Aire Nuestro es una cadena de alta cultura televisiva" [2009: 9]), que es otro de los vértices temáticos más comentados por la crítica (A. J. Rodríguez 2008, Fernández Porta 2008, Alarcón Sierra 2012) y una de las características de la sátira menipea (Duval 2007: 72) ${ }^{11}$. Esta unión libre y desprejuiciada es también parte de los recursos humorísticos concretos de la obra de Vilas, puesto que supone una incongruencia en la mente del lector el encuentro de personajes de mundos culturales o temporales diferentes o su colocación en lugares nunca esperados. Es lo que podemos llamar misplacement, un procedimiento que juega con las expectativas del lector sobre los personajes ficcionalizados tomados de la realidad, que es uno de los recursos más repetidos de Listen to me, plagado de diálogos que podemos llamar lucianescos (Obama con Sabato, Vilas con Dylan, con Hegel, con Lenin, Kafka, Juan Carlos I, San Pedro, Marx, y por supuesto con Dios [2013: 47, $48,51,57,68,70-1,99,102])^{12}$.

También es continua la referencia a todo aquello que tenga que ver con el materialismo carnal o placentero: el sexo, la ebriedad, la comida, la visión casi futurista de la belleza de los coches: desde referencias a los penes de Aristóteles, Platón, Mozart o Santo Tomás (2002: 76), a capítulos completos de enumeraciones de exaltación de la comida (2004: 115 y ss.), pasando por poemas titulados "AUDI 100", "SEAT 850", "HU-4091-L" o "MAZDA 6" (2010: 179-83, 225-27, 236-39). Incluso es recurrente todo el campo semántico de las entrañas, los excrementos o la orina (2002: 14, 18; 2008: 135, 189; 2009: 79-81). También aparece el requisito de la parodia recurrente del culto religioso, el rebajamiento de lo sagrado (Bajtín 1989: 12 y 334), que se hace presente de forma constante: plegarias blasfemas como "Húmedos misterios hiperdivinos y teológicos, mingas meningíticas nos dé Dios todos los domingos, grandes carnavales de carne desnuda nos traiga este mundo" (2004: 93), aparentes oxímoros ("esta deformidad Santa, santidad monstruosa" [2004: 180]), ángeles bajados a la tierra (2002: 73, 122; 2012b: 90), Dios y lo sagrado desacralizado (2002: 136; 2004: 63; 2013: 104-105), convertido incluso en nevera (sic) (2002: 122), María Magdalena convertida en Lena, prostituta moderna (2004: 183), y otras figuras, sin embargo, sacralizadas: Baltasar ("ese negrata parece el hijo de Dios") en Magia (2004: 21), el narrador ("el Espíritu Santo, ah, chaval, ese soy yo") (2004: 178), Sarapo como Cristo y Edith Piaf como

\footnotetext{
11 ... "combining the incompatible registers and genres of high and low culture in fantastical comic fictions and freewhiling, antinormative, even subversive criticism".

12 Para ver más ejemplos en otras obras: 2002: 33 y 143; 2009; 2012b: 82, 97, 117 y ss, 147, 164, 174.
} 
"Virgen nueva" (2008: 49), etc. En relación a esto encontramos la desentronización, en la obra de Vilas plasmada en la continua alusión al rey Juan Carlos I (ya en Zeta, pero sobre todo en Aire nuestro, Los inmortales y Listen to me), utilizado como personaje y rebajado en su plasmación siempre paródica; por otro lado, en esta misma lógica se encuentra la inversión de roles y la recurrencia del disfraz: "un hombre y un perro intercambiados" (2004: 107), un grupo disfrazado con caretas de los poetas de la generación del 27 (2009: 222-23) o los continuos juegos con la disposición de los nombres (José Luis Valente, Pedro Cernuda, Luisa Borges en Aire Nuestro, o las fotos de Sergio Gaspar o el mismo Vilas unidas a los nombres de Aznar o Felipe González en Los inmortales), llevada al extremo en dos narraciones en las que el nombre de un personaje va variando continuamente de una frase a la siguiente, como si fuese una continua reencarnación narratológica (2008: 53-61; 2009: 224-38). Todas estas técnicas forman parte de un mismo travestismo estético e identitario irreverente y sublevador.

Estilísticamente la obra de Vilas cumple en su expresionismo exacerbado con el realismo grotesco que relaciona Bajtín con el carnaval: "la exageración, el hiperbolismo, la profusión, el exceso son, como es sabido, los signos característicos más marcados del estilo grotesco" (1989: 273). En Vilas una buena parte del asentamiento del humor está en esa sensación festiva que da la hipérbole constante (puede ejemplarizarse con la condensación en la palabra Cetísima) y la abundancia desbordante en la expresión y la fabulación.

El carnaval como celebración festiva popular que responde a una necesidad antropológica de una época determinada es trasladable, mediante la teoría bajtiniana de la carnavalización, a la literatura de diferentes épocas. El concepto de carnaval bajtiniano ha recibido críticas por la falta de precisión histórica de su propuesta conceptual ${ }^{13}$, pero él no tuvo problemas en admitir que su utilización del término y el concepto del carnaval no era estricta, sino ensanchada ${ }^{14}$, de manera que la aplicabilidad de su propuesta crece en sus posibilidades. Tal como la presentamos la risa carnavalesca del carnaval bajtiniano es, por tanto, el presupuesto teórico más hábil para la comprensión orgánica de la obra humorística vilasiana.

\section{LA OBRA HUMORÍSTICA VILASIANA COMO SÁTIRA MENIPEA}

Hemos comentado ya cómo uno de los elementos más referidos por la crítica sobre la obra de Vilas es la cuestión genérica, tanto por la hibridación y las concomitancias entre su obra lírica y narrativa como por la denominación

\footnotetext{
13 Un ejemplo puede ser la crítica del gran medievalista Aaron Gurevich, que defiende que el carnaval solo aparece al final de la Edad Media (1999: 57).

${ }^{14}$ El carnaval "[r]epresenta el elemento más antiguo de la fiesta popular, y podemos asegurar, sin riesgo de equivocarnos, que es el fragmento mejor conservado de ese mundo inmenso y rico. Esto nos permite utilizar el adjetivo «carnavalesco» en una acepción más amplia que incluye no sólo las formas del carnaval en el sentido estricto y preciso del término, sino también la vida rica y variada de la fiesta popular en el curso de los siglos y bajo el Renacimiento" (Bajtín 1989: 196).
} 
discutida de "novela" para sus obras España, Aire Nuestro o Los inmortales ${ }^{15}$. La cuestión, sabido y asumido el fragmentarismo y a la vez la unidad de voz, tono y estilo de la obra de Vilas, no nos parece muy relevante, pero sí la apreciación de Teresa Gómez Trueba al glosar el debate que se dio en 2009 con la publicación de Aire nuestro:

Para Vilas, el imperativo del género de la novela [...], no tiene tanto que ver con unas exigencias formales, sino más bien con una exigencia moral, que él relaciona con la pertinencia de lo narrado. "Entiendo por novela un acto de conciencia que afirma la vida", sostiene Manuel Vilas. (Gómez Trueba 2013: 67-68)

Partiendo de esta visión y viendo la similitud y la unidad que creemos apreciar en la serie de obras vilasianas que estudiamos, estimamos conveniente plantear el asunto del género literario desde un punto de vista no formal, sino teniendo en cuenta los puntos claves de la interpretación vilasiana y partiendo de la carnavalización característica de su obra como componente que tiende puentes, como hemos visto, entre esos elementos: vitalismo, ambigüedad ideológica, mezcla de alta y baja cultura, autoficción, humor e indeterminación genérica. Todo esto tiene que ver con ser una literatura carnavalizada, que continúa la carnavalización literaria que se desarrolló desde la Antigüedad. Dentro de los géneros de literatura carnavalizada, de la tradición de lo serio-cómico (el spoudogeloion), la obra humorística de Vilas se nos presenta toda ella como una actualización de la sátira menipea. Las características de la sátira menipea clásica, de hecho, incluyen muchos de esos componentes que la carnavalización pone en relación, como la autoficción: "in the Menippean narrative the author often identifies himself with the (unreliable) narrator as a way of self-parody" (Smet 1996: 30). Un par de críticos ya han relacionado alguna de las obras de Vilas con este género carnavalesco: Luis Beltrán Calor y España (2009: 35) y Domingo Ródenas Los inmortales (2012), pero creemos que todas las obras humorísticas de Vilas son variaciones de la sátira menipea.

La caracterización genérica de la sátira menipea está en relación con la risa ambivalente, democrítea, melancólica que veíamos en Vilas ya desde la Anatomía de la melancolía de Robert Burton (1621), considerada una sátira menipea (el personaje es Demócrito Jr. $)^{16}$ y razón de que Northrop Frye, uno de los más importantes estudiosos de la menipea en el siglo xx con su Anatomy of Criticism (1957), propusiera cambiar la etiqueta de "sátira menipea" por "anatomía" para el género en la actualidad (1973: 311-312).

\footnotetext{
${ }^{15}$ Podemos apuntar como causa de este debate la clara falta de una única línea argumental, con una estructura de multiplicación digresiva que, adelantamos, es característica de la sátira menipea en la que pretendemos englobar sus obras (vid. la definición de Relihan en Smet 1996: 30: "wildly toleration of digression", "no driving unity of purpose", etc.). Por otro lado, los estudiosos de la sátira menipea (Frye, Bajtín, Relihan, Blanchard o Weinbrot) están de acuerdo en la dificultad de su definición (Quintero 2007: 7-8) (como los de Vilas en la complejidad de su etiquetado).

16 ... "the greatest Menippean satire in English before Swift, Burton's Anatomy of Melancholy" (Frye 1973: 311).
} 
Veamos las características que los expertos -especialmente Bajtín- apuntan del género y cómo la obra de Vilas encaja a la perfección con ellas:

La oscilación del elemento de la risa (Bajtín 2005: 166) explica que algunas de estas obras tengan un humor más atenuado o más oscurecido, como las iniciales Zeta y Magia, como vimos en las primeras críticas. La absoluta libertad de inventiva, sin necesidad de ajustarse a las exigencias de verosimilitud externa y utilizando recurrentemente la aventura y la fantasía, pero pudiendo los personajes ser históricos o legendarios, es otro de los elementos que apuntan Bajtín (2005: 167) o Joel C. Relihan (apud Smet 1996: 30). Ya vimos cómo la fabulación abundantísima y el carnaval de ficciones multiplicadas era una de las características de estas obras, de una inverosimilitud extrema en cuanto a lo real, y que sin embargo acogen el continuo desfilar de infinitud de figuras históricas y personajes públicos, generalmente mezclados.

Es fácil apreciar igualmente la combinación de la libre fantasía, el simbolismo y a veces el elemento místico-religioso con un "naturalismo de bajos fondos" sumamente extremo y grosero (Bajtín 2005:168): los diálogos con Dios de Listen to me, o la obsesión vilasiana por la santidad son buenos ejemplos de lo místico-religioso, aunque ironizado, mientras que lo grosero, desde el vocabulario a los instintos más bajos aparecen continuamente ("Fiesta y miseria, always" [2012b: 194]), incluso en forma de enumeración (vid. 2004: 88).

La propugnación del humor como manera de ver el mundo y no como retórica es ya indicador del universalismo filosófico, la extrema capacidad de contemplación del mundo, la risa no como entretenimiento, sino como búsqueda de la verdad, que es otra de las características del género (Bajtín 2005: 169; también durante la época humanista: "humanist Menippean satire fulfills in prosimetric style that commonly recognized function of Classical satire phrased by Horace as 'ridentem dicere verum'" [Smet 1996: 70]): la comprensión de la obra de Vilas como política que ha hecho parte de la crítica se refiere, en última instancia, a este carácter.

La estructura en tres planos -tierra, cielo, infiernos- es otro de los elementos señalados por Bajtín (2005: 169) y que aparece explícitamente en varias de sus obras, con las continuas referencias al Purgatorio, donde conviven escritores de diferentes épocas (2008: 85 y ss.; 2009: 57 y ss.). Esto está ligado a la observación desde un punto de vista inusitado, por ejemplo desde la altura (Bajtín 2005: 170): se hace explícito en la vista de Zeta desde las alturas en el relato del ascensor de Zeta (2002: 73), o con los personajes gigantes sobrevolando la ciudad en Magia (2004: 188), pero en general el punto de vista o la focalización de la narración, polifónica y cambiante, siempre resulta excéntrico.

Otro de los elementos de caracterización genérica es la experimentación psicológico-moral: la representación de estados inhabituales, anormales, psíquico-morales, toda clase de demencias, desdoblamientos de la personalidad, ilusiones irrefrenables, sueños raros, pasiones que rayan en la locura, etc. (Bajtín 2005: 170), todo lo cual es bastante habitual en la obra humorística de Vilas, con personajes en el psiquiátrico (Baltasar en Magia, Corman Martínez en Los inmortales), sueños continuos -el llamado "dream framework", elemento tan 
importante en la menipea desde Justo Lipsio (vid. Smet 1996: 87-116)- (2002: 14; 2008: 85 y ss., 163; 2009: 194, 224; 2012b: 147), o visiones (el fantasma de Stalin presentándose a Corman [2012b: 59], el de Joyce mostrándose ante Dante y Neruda [2012b: 82], etc.).

Por último, una característica diferencial importante de la menipea clásica, el prosimetrum -mezcla de prosa y verso- (Smet 1996: 23 y ss.), se realiza en su actualización en el amplio uso de géneros intercalados, señalado por Bajtín como otro de los elementos diferenciadores (2005: 173), y clave en la obra de Vilas. Por un lado, con la inclusión de elementos narrativos en la lírica y de poemas en la narrativa, con la indefinición o hibridación, y con el ejercicio del género de la menipea en obras tanto en verso como en prosa, de mayor y menor extensión; por otro, con obras de diferentes grados de ficcionalización e incluso con la inserción de unas en otras; no es difícil detectar muchos fragmentos de Zeta, España o Los inmortales, con algunas variaciones, en la recopilación de artículos que es Arde el sol sin tiempo, o incluso un artículo de Heraldo de Aragón escaneado o un fragmento de España en Aire nuestro (2009: 206 y 250-251). Habría que incluir también aquí, además de la mezcolanza genérica, la intermedial, con la continua incorporación de fotografías, letras musicales, etc.

\section{CONCLUSIÓN}

El conjunto de obras de Manuel Vilas formado por Zeta, Magia, España, Aire Nuestro, Los inmortales, El Cielo, Resurrección, Calor, Gran Vilas, Listen to me y Arde el sol sin tiempo forman una unidad en cuanto a su visión del mundo y su tratamiento de lo humorístico, configurada desde un punto de vista tragicómico y que entronca con lo profundo de la experiencia humana - de ahí la ambivalencia y la ambigüedad de la risa vilasiana-, y ligada a la risa antigua y popular, relacionada con la carnavalización e identificable como actualización de la tradición genérica de la sátira menipea.

\section{OBRAS CITADAS}

Acín, Ramón (2010): "Conocer la realidad, no huir de ella", Cuadernos Hispanoamericanos, vol. 717, n. ${ }^{\circ}$ 3, pp. 131-135.

Alarcón Sierra, Rafael (2012): "Amor (poesía reunida 1988-2010), de Manuel Vilas", Paraíso: Revista de poesía, vol. 8, pp. 31-40.

Bajtín, Mijail (1989): La cultura popular en la Edad Media y en el Renacimiento. El contexto de François Rabelais. Madrid, Alianza.

- (2005): Problemas de la poética de Dostoievski. México, Fondo de Cultura Económica.

Ballart, Pere (1994): Eironeia. La figuración irónica en el discurso literario moderno. Barcelona, Quaderns Crema.

Beltrán, Luis (2002): La imaginación literaria. La seriedad y la risa en la literatura occidental. Barcelona, Montesinos.

_ (2009): "La risa y cuarenta millones", Ínsula, vol. 748, n. ${ }^{\circ}$ 3, pp. 34-35. 
Benéitez, Rosa (2009a): "El mito de la identidad en España, de Manuel Vilas". En: Fidel López Criado (ed.): Héroes, mitos y monstruos en la literatura española contemporánea. Santiago de Compostela, Andavira Editora, pp. 165-170.

- (2009b): "El Aire nuestro de Vilas ya es de todos", Afterpost: <http://afterpost. wordpress.com/2009/12/20/el-aire-nuestro-de-vilas-ya-es-de-todos/> [última visita: 30.09 .2014$]$.

Bevis, Matthew (2013): Comedy. A Very Short Introduction. Oxford, Oxford University Press.

Bobes, Carmen (2010): "Falta de humor en la gran narrativa hispanoamericana". En: Ulpiano Lada Ferreras y Álvaro Arias-Cachero Cabal (eds.): Literatura y humor. Estudios teórico-críticos. Oviedo, Servicio de publicaciones de la Universidad de Oviedo, pp. 13-41.

Bremmer, Jan (1999): "Chistes humoristas y libros de chistes en la antigua Grecia". En: Jan Bremmer y Herman Roodenburg (coords.): Una historia cultural del humor. Desde la Antigüedad a nuestros días. Madrid, Sequitur, pp. 11-28.

Bubnova, Tatiana (2000): "Varia fortuna de la "cultura popular de la risa»". En Tatiana Bubnova (ed.): En torno a la cultura popular de la risa. Barcelona, Anthropos, pp. 135-163.

Buceta, Olalla et al. (2014): "Un breve análisis del humor en Occidente", Cuadernos de Aleph, n. ${ }^{\circ}$ 6, pp. 1-24.

Caballero, Marta (2009): "Manuel Vilas: «Aire nuestro no es una novela sobre televisión, es una televisión»", El Mundo. El cultural, 9 de junio. Disponible en <http://www. elcultural.es/noticias/letras/Manuel-Vilas-Aire-Nuestro-no-es-una-novela-sobretelevision-es-una-television/505552> [última visita: 30.09.2014].

Calles, Jara (2011): Literatura de las nuevas tecnologías. Aproximación estética al modelo literario español de principios de siglo (2001-2011). Tesis doctoral inédita. Universidad de Salamanca.

Calvo, Javier (2009): "Primer Álbum: Aire Nuestro de Manuel Vilas", Quimera, vol. 313, n. ${ }^{\circ}$ 11, pp. 92-95.

_ (2010): “Un texto de Javier Calvo sobre mi relato «Selene Trips» publicado en el último número de la revista Eñe", Blog de Manuel Vilas: <http://manuelvilas.blogspot.com. es/2010/10/un-texto-de-javier-calvo-sobre-mi.html> [última visita: 30.09.2014].

Camero, Francisco (2014): "Manuel Vilas: «Un escritor se debe a la vida y no al prejuicio sobre la vida»", Diario de Sevilla, 12 de agosto. Disponible en <http://www.diariodesevilla. es/article/delibros/1832495/escritor/se/debe/la/vida/y/no/prejuicio/sobre/la/vida. html> [última visita: 30.09.2014].

Cilleruelo, José Ángel (2006), "Muerte y resurrección del «yo» en la poesía de Manuel Vilas". En: El invisible anillo, vol. 1, pp. 20-24.

Company, Flavia (2008): "Narrativa de riesgo excitante y divertida", El Periódico de Cataluña, 23 abril, p. 76.

Consuegra, Cristina (2012): "Manuel Vilas: «Gran Vilas es un título erótico»", Culturamas: <http://www.culturamas.es/blog/2012/08/19/gran-vilas-es-un-titulo-erotico/> [última visita: 30.09.2014].

Costa, Jordi (2010): "La (im)posibilidad de una risa. Donde la comedia pierde su nombre". En: Jordi Costa (ed.): Una risa nueva. Posthumor, parodias y otras mutaciones de la comedia. Molina de Segura, Nausícaä, pp. 9-28. 
Cutler Shershow, Scott (1986): Laughing Matters: The Paradox of Comedy. Massachusetts, University of Massachusetts Press.

Díez Caviedes, Rubén y G. J., Ricardo (2014): "Manuel Vilas: «Elvis cambió el mundo tanto como lo pudo cambiar Freud con el psicoanálisis»", Jot Down: <http://www. jotdown.es/2014/01/manuel-vilas-elvis-cambio-el-mundo-tanto-como-lo-pudocambiar-freud-con-el-psicoanalisis/> [última visita: 30.09.2014].

Divisa, Javier (2014): "Zeta, Manuel Vilas", Tarántula. Revista cultural: < http://revistatarantula. com/zeta-manuel-vilas/> [última visita: 30.09.2014].

Duval, Edwin M. (2007): "Rabelais and French Renaissance Satire". En Rubén Quintero (ed.): A Companion to Satire. Oxford, Blackwell, pp. 70-85.

Espigado, Miguel (2009): "Escribir con el cuerpo", Quimera, vol. 303, n. ${ }^{2}$, pp. 15-17.

Fernández Porta, Eloy (2008): "Los desafectos de la patria", página de DVD Ediciones, sección Firmas invitadas: <http://www.dvdediciones.com/firmas_vilas.html> [última visita: 30.09 .2014$]$.

Ferré, Juan Francisco (2008): "La España de Vilas", Diario sur, 25 de abril. Disponible en: <http://juanfranciscoferre.wordpress.com/2008/10/31/la-espana-de-manuelvilas/> [última visita: 30.09 .2014$]$.

_ (2012): "Una historia cómica de España", Blog de Juan Francisco Ferré: <http:// juanfranciscoferre.blogspot.com.es/2012/05/una-historia-comica-de-espana. html> [última visita: 30.09.2014].

Fontana, Antonio (2009): "Entrevista a Manuel Vilas", $A B C D, 5$ de diciembre.

Freudenburg, Kirk (2005): "Roman satire". En Kirk Freudenburg (ed.): The Cambridge Companion to Roman Satire. Cambridge, Cambridge University Press, pp. 1-30.

García Jambrina, Luis (2008): "Agente provocador", $A B C D, 17$ mayo.

Gómez, Sonia (2015): "Juegos autoficcionales en la obra de Manuel Vilas", Pasavento. Revista de estudios hispánicos, vol III, n. ${ }^{0}$ 1, pp. 155-169.

- (2013): "Refracción y transformación del humor jardeliano en la narrativa de Manuel Vilas". En: Marco Kunz y Sonia Gómez (eds.): Nueva narrativa española. Barcelona, Linkgua, pp. 171-193.

Gómez Barranco, Salvador (2014): "La fiesta de la autoficción en las novelas de Manuel Vilas", LL Journal vol. 9, n. ${ }^{\circ}$ 2. Disponible en: <http://lljournal.commons.gc.cuny. edu/gomez-barranco-texto/> [última visita: 25.05.2015].

Gómez Trueba, Teresa (2013): "Fragmentación extrema en la no-vela del siglo xxI: Mora, Vilas y Fernández Mallo". En: Marco Kunz y Sonia Gómez (eds.): Nueva narrativa española. Barcelona, Linkgua, pp. 57-76.

Guinda, Ángel (2009): "El realismo amable de Manuel Vilas", Cuadernos del matemático, vol. 41-42, n. ${ }^{\circ}$, pp. 201-202.

Gurevich, Aaron (1999): "Bakhtin y el carnaval medieval". En: Jan Bremmer y Herman Roodenburg (coord.): Una historia cultural del humor. Desde la Antigüedad a nuestros días. Madrid, Sequitur, pp. 55-61.

Hernández, José Antonio (2010): "El humor: un procedimiento creativo y recreativo". En: Ulpiano Lada Ferreras y Álvaro Arias-Cachero Cabal (eds.): Literatura y humor. Estudios teórico-críticos. Oviedo, Servicio de publicaciones de la Universidad de Oviedo, pp. 43-56. 
Holland, Norman N. (1982): Laughing. A Psychology of Humor. Ithaca, Cornell University Press.

Le Goff, Jacques (1999): "La risa en la Edad Media". En: Jan Bremmer y Herman Roodenburg (coord.): Una historia cultural del humor. Desde la Antigüedad a nuestros días. Madrid, Sequitur, pp. 41-54.

Llamazares, Javier (2014): "Un verano de sol y playa", El Diario montañés, 3 de julio. Disponible en: <http://www.eldiariomontanes.es/culturas/libros/201407/02/ verano-letras-20140702192232.html> [última visita: 30.09.2014].

Marías, Fernando (2013): "Puertas, latigazos y dioses", Blog de Fernando Marías en Anika entre Libros: <http://www.anikaentrelibros.com/blogs/fernandomarias/2013/12/20/puertas--latigazos-y-dioses/> [última visita: 30.09.2014].

Marqués, Juan (2008): "Calor, de Manuel Vilas", Cuadernos Hispanoamericanos, vol. 700, n. ${ }^{\circ}$ 10, pp. 102-106.

Marzal, Carlos (2009): "Aire nuestro, de Manuel Vilas", ABC Valencia, 24 octubre. Mayor, David (2008): "España, de Manuel Vilas", Turia, vol. 87, n. ${ }^{\circ} 2$, pp. 411-413.

Menéndez Salmón, Ricardo (2008): "Contra los tibios", El Comercio, 29 de octubre.

Mesa, Sara (2014): "Blandengue y vampírica España", Estado Crítico: <http://www. criticoestado.es/blandengue-y-vampirica-espana/> [última visita: 30.09.2014].

Miñana, Luisa (2008): "España, Manuel Vilas", El cronista de la red: <http://www.aragoneria. com/cronista/17/espana.htm> [última visita: 30.09.2014].

Miranda, Roberto (2008): "Una voz en el desierto", El Periódico de Aragón, 14 de junio.

Mora, Vicente Luis (2008): "Frankenstein reflexiona", Quimera, vol. 295, pp. 72-73.

Moreno, Fernando Ángel (2014): "Listen to me, Manuel Vilas", La tormenta en un vaso: <http://latormentaenunvaso.blogspot.com.es/2014/01/listen-to-me-manuelvilas.html?utm_source $=$ feedburner\&utm_medium $=$ email\&utm_campaign $=$ Fee d\%3A+blogspot\%2FvbtoL+\%28La+Tormenta+en+un+Vaso\%29> [última visita: 30.09.2014].

Moreno, Javier (2008): "España, de Manuel Vilas", Deriva: <http://deriva.org/articulos/ articulos.php?ID=402> [última visita: 30.09.2014].

Olmos, Alberto (2009): "Aire nuestro, Manuel Vilas", Literaturas.com: <http://www. literaturas.com/v010/index0912revista.asp> [última visita: 30.09.2014].

Olson, Elder; Wardropper, B. W. (1978): Teoría de la comedia. La comedia española del Siglo de Oro. Barcelona, Ariel.

Paraíso, Isabel (2001): Las voces de Psique. Murcia, Universidad de Murcia.

- (2002): "Los procedimientos de lo risible según Cicerón". En: José Antonio Hernández Guerrero et al. (eds.): Humor y las ciencias humanas. Cádiz, Fundación Municipal de Cultura Ayuntamiento de Cádiz-Servicio de Publicaciones de la Universidad de Cádiz, pp. 73-83.

Paz Soldán, Edmundo (2008): "La España de Manuel Vilas", Río fugitivo, blog de Edmundo Paz Soldán en El Boomeran(g): <http://www.elboomeran.com/blog-post/117/3944/ edmundo-paz-soldan/la-espana-de-manuel-vilas/> [última visita: 30.09.2014].

Pozuelo Yvancos, José María (2009): "Sátira y carnaval", $A B C D, 5$ de diciembre.

Pueo, Juan Carlos (2002): Los reflejos en juego (Una teoría de la parodia). Valencia, Tirant lo Blanc. 
Pujante, Pedro (2014): "Zeta, de Manuel Vilas", Acantilados de papel: <http:// acantiladosdepapel.blogspot.com.es/2014/07/z-de-manuel-vilas-resena-n-678. html> [última visita: 30.09.2014].

Quintero, Ruben (2007). "Understanding satire". En: A Companion to Satire. Oxford, Blackwell, pp. 1-11.

Reig, Rafael (2010), "El collar de perlas", ABCD, 13 de febrero.

Rocamora, Jesús (2012): "Entrevista a Manuel Vilas: «Busco en la literatura el estallido total, el carnaval interminable»", Público, 25 de enero.

Ródenas de Moya, Domingo (2012): "El carnaval de la muerte", El Periódico, 22 de febrero. Disponible en <http://www.elperiodico.com/es/noticias/ocio-y-cultura/carnavalmuerte-1438439> [última visita: 30.09.2014].

Rodríguez, Antonio J. (2008): "España, de Manuel Vilas", El día, 25 de mayo.

— (2009): "Déjà vu", Quimera, vol. 313, n. ${ }^{0} 11$, pp. 96-97.

Rodríguez, Emma (2012): "«No interesa que la obra perdure, se quiere el éxito ya»", El Mundo, 31 enero.

Rodríguez, Josep María (2011): "Intensidad y altura". En Cuadernos Hispanoamericanos, vol. 728, pp. 139-141.

Sanz Villanueva, Santos (2012): "Los inmortales", El Cultural, 20 de enero.

Serrano Larraz, Miguel (2012): "Sólo puede quedar uno", Turia, vol. 103, pp. 413-6.

Smet, Ingrid A. R. de (1996): Menippean satire and the Republic of Letters. 1581-1655. Ginebra, Droz.

Suárez Plácido, Rafael (2009): “El año de Vilas", Beta, abril-junio.

Vilas, Manuel (2002): Zeta. Barcelona, DVD.

— (2004): Magia. Barcelona, DVD.

- (2008): España. Barcelona, DVD.

- (2009): Aire nuestro. Madrid, Alfaguara.

— (2010): Amor. Poesía reunida. 1988-2010. Madrid, Visor.

- (2012a): Gran Vilas. Madrid, Visor.

- (2012b). Los inmortales. Madrid, Alfaguara.

- (2013): Listen to me. Córdoba, La Bella Varsovia.

(2014a): Arde el sol sin tiempo. Artículos y literatura en pequeñas dosis. Valladolid, Servicio de Publicaciones de la Universidad de Valladolid.

— (2014b): "Entrevista a Manuel Vilas", lowa Literaria. Disponible en <https://www. youtube.com/watch?v=MlvoN90XcRQ> [última visita: 30.09 .2014 ]. 